Pacific Journal of Mathematics

OSCILLATORY PROPERTIES OF SOLUTIONS OF EVEN 


\title{
OSCILLATORY PROPERTIES OF SOLUTIONS OF EVEN ORDER DIFFERENTIAL EQUATIONS
}

\author{
HIROSHI ONOSE
}

\begin{abstract}
Consider the following $n$th order nonlinear differential equation

$$
x^{(n)}+f\left(t, x, x^{\prime}, \cdots, x^{(n-1)}\right)=0 .
$$

All functions considered will be assumed continuous and all the solutions of (1), continuously extendable throught the entire nonnegative real axis. A nontrivial solution of (1) is called oscillatory if it has zeros for arbitrarily large $t$ and equation ( 1 ) is called oscillatory if all of its solutions are oscillatory. A nontrivial solution of (1) is called nonoscillatory if it has only a finite number of zeros on $\left[t_{0}, \infty\right)$ and equation (1) is called nonoscillatory if all of its solutions are nonoscillatory. In this paper, theorems on oscillation and nonoscillation are presented.
\end{abstract}

Recently, J. S. W. Wong [8] posed a definition called strongly continuous with which he proved some theorems to (1) for $n=2$. The proof is based on that of his earlier results [7]. We introduce more general definition. A function $f\left(t, x_{1}, \cdots, x_{n}\right)$ is called generalized strongly continuous from the left at $x_{1 c}$ if $f\left(t, x_{1}, x_{2}, \cdots, x_{n}\right)$ is jointly continuous in $t$ and $x_{i}(i=1,2, \cdots, n)$ and for $\varepsilon>0$ there exist $\delta>0, T \geqq 0$, and $x_{\delta} \in\left[x_{1 c}-\delta, x_{1 c}\right]$ such that for all $x_{1} \in\left[x_{1 c}-\delta, x_{1 c}\right]$, and for all $x_{i}$ satisfying $\left|x_{i}-k_{i}\right| \leqq \delta$ ( $k_{i}$ is any constant) for $i=$ $2, \cdots, T$,

$$
(1-\varepsilon) f\left(t, x_{\delta}, k_{2}, \cdots, k_{n}\right) \leqq f\left(t, x_{1}, \cdots, x_{n}\right) \leqq(1+\varepsilon) f\left(t, x_{1 c}, k_{2}, \cdots, k_{n}\right) \text {, }
$$

for all $t \geqq n$.

Generalized strong continuity from the right is defined analogousely. A function $f\left(t, x_{1}, \cdots, x_{n}\right)$ is said to be generalized strongly continuous if it is generalized strongly continuous both from the left and from the right. If $f=f\left(t, x_{1}\right)$, then our definition is the same as Wong's one. For example, $f\left(t, x_{1}, \cdots, x_{n}\right)=a(t) f\left(x_{1}, \cdots x_{n}\right)$ is generalized strongly continuous.

2. Oscillation and nonoscillation theorems.

\section{THEOREm 1. Assume that $n$ is even and that}

(a) $f\left(t, c, k_{2} \cdots, k_{n}\right)$ is bounded for any constant $c$ and $k_{i}(i=2, \cdots, n)$ and $x_{1} f\left(t, x_{1}, \cdots, x_{n}\right)>0\left(x_{1} \neq 0\right)$.

Let $f\left(t, x_{1}, \cdots, x_{n}\right)$ be generalized strongly continuous from the left 
for $x_{1}>0$ and generalized strongly continuous from the right for $x_{1}<0$. Then, a necessary and sufficient condition for equation (1) to have a bounded nonoscillatory solution is

$$
\left|\int^{\infty} t^{n-1} f\left(t, c, k_{2}, \cdots, k_{n}\right) d t\right|<\infty
$$

$\left(c(\neq 0)\right.$ and $k_{i}(i=2, \cdots, n)$ are some constants $)$.

Proof. Let $x(t)$ be a bounded nonoscillatory solution of (1), which must eventually be of one sign. Then we may assume that $x(t)>0$ for $t \geqq T>0$. Since $x(t)>0$, then $f\left(t, x, x^{\prime}, \cdots, x^{(n-1)}\right)>0$ for $t \geqq T$, we see from (1) and the assumption that $x(t)$ is bounded:

$$
\begin{aligned}
& x^{(n)} \leqq 0, x^{(n-1)} \geqq 0, x^{(n-2)} \leqq 0, \cdots, x^{\prime} \geqq 0, \\
& \lim _{t \rightarrow \infty} x^{(i)}(t)=0, \quad i=1,2, \cdots, n-1 .
\end{aligned}
$$

From this and the fact $x(t)$ is positive and bounded implies that $x(t)$ tends to a finite limit $L>0$. Integrating (1), we obtain for sufficiently large $t$

$$
\begin{array}{r}
x^{(n-i)}(t)=(-1)^{n-i-1} \int_{t}^{\infty} \frac{(s-t)^{i-1}}{(i-1) !} f\left(s, x(s), x^{\prime}(s), \cdots, x^{(n-1)}(s) d s\right. \\
(\text { for, } i=1,2, \cdots, n-1) .
\end{array}
$$

In particular,

$$
x(t)=L-\int_{t}^{\infty} \frac{(s-t)^{n-1}}{(n-1) !} f\left(s, x(s), x^{\prime}(s), \cdots, x^{(n-1)}(s)\right) d s .
$$

By the generalized strong continuity of $f\left(t, x_{1}, x_{2}, \cdots, x_{n}\right)$ implies that there exist $0<\delta<L$, and $L_{i} \in[L-\delta, L]$ such that for all $x_{i}$ satisfying $\left|x_{i}-k_{i}\right| \leqq \delta(i=2, \cdots, n)$ and for all $x_{1} \in[L-\delta, L]$,

$$
f\left(t, x_{1}, x_{2}, \cdots, x_{n}\right) \geqq \frac{1}{2} f\left(t, L_{\delta}, k_{2}, \cdots k_{n}\right) .
$$

Choose $T$ sufficiently large, we can restrict the solution $x(t)$ to satisfy $L-\delta \leqq x(t) \leqq L$ for all $t \geqq T$, and that

$$
\left|x^{(i)}(t)-0\right| \leqq \delta(i=1,2, \cdots, n-1),
$$

for all $t \geqq T$.

Thus, we obtain for $t \geqq T$,

$$
0<\frac{1}{2} f\left(t, L_{\delta}, 0, \cdots, 0\right)<f\left(t, x(t), x^{\prime}(t), \cdots, x^{(n-1)}(t)\right) .
$$


Accordingly, we obtain

$$
\begin{aligned}
x(t) & =L-\int_{t}^{\infty} \frac{(s-t)^{n-1}}{(n-1) !} f\left(s, x(s), x^{\prime}(s), \cdots, x^{(n-1)}(s)\right) d s \\
& \leqq L-\frac{1}{2(n-1) !} \int_{t}^{\infty}(s-t)^{n-1} f\left(s, L_{\delta}, 0, \cdots, 0\right) d s .
\end{aligned}
$$

Since $x(t)$ is bounded, we obtain

$$
\int_{t}^{\infty}(s-t)^{n-1} f\left(s, L_{\delta}, 0, \cdots, 0\right) d s<\infty,
$$

which implies

$$
\int_{t}^{\infty} s^{n-1} f\left(s, L_{\delta}, 0, \cdots, 0\right) d s<\infty .
$$

Conversely, we show that if (2) holds for some constant $c>0$ and $k_{i}(i=2, \cdots, n)$, then there exists a nonnegative continuous bounded solution to the following integral equation:

$$
\begin{aligned}
x_{n-1}(t) & =k_{n}+\int_{t}^{\infty} f\left(s, x_{0}(s), x_{1}(s), \cdots, x_{n-1}(s)\right) d s \\
x_{n-2}(t) & =k_{n-1}-\int_{t}^{\infty}(s-t) f\left(s, x_{0}(s), x_{1}(s), \cdots, x_{n-1}(s)\right) d s \\
x_{n-3}(t) & =k_{n-2}+\int_{t}^{\infty} \frac{(s-t)^{2}}{2 !} f\left(s, x_{0}(s), x_{1}(s), \cdots, x_{n-1}(s)\right) d s \\
\vdots & \\
x_{0}(t) & =c-\int_{t}^{\infty} \frac{(s-t)^{n-1}}{(n-1) !} f\left(s, x_{0}(s), x_{1}(s), \cdots, x_{n-1}(s)\right) d s .
\end{aligned}
$$

We define $E=\{0,1,2, \cdots, n-1\}$. Let a positive number $T$ be chosen such that

$$
\max _{i \in E} \frac{1}{(n-1-i) !} \int_{t}^{\infty}(s-t)^{n-1-i} f\left(s, c, k_{2}, \cdots, k_{n}\right) d s \leqq \frac{c}{M}
$$

where $M(>2)$ is some constant.

We define. for $N$ a positive interger $N \geqq T$ : for $t \geqq N$,

$$
\begin{aligned}
x_{n-1, N}(t) & =k_{n} \\
x_{n-2, N}(t) & =k_{n-1} \\
\vdots & \\
x_{1, N}(t) & =k_{2} \\
x_{0, N}(t) & =c
\end{aligned}
$$

and for $T \leqq t \leqq N$, 
(8)

$$
\begin{aligned}
x_{n-1, N}(t) & =k_{n}+\int_{t+(1 / N)}^{\infty} f\left(s, x_{0, N}(s), x_{1, N}(s), \cdots, x_{n-1, N}(s)\right) d s \\
x_{n-2, N}(t) & =k_{n-1}-\int_{t+(1 / N)}^{\infty}\left(s-t-\frac{1}{N}\right) f\left(s, x_{0, N}(s), \cdots, x_{n-1, N}(s)\right) d s \\
\vdots & \\
x_{1, N}(t) & =k_{2}+\int_{t+(1 / N)}^{\infty} \frac{\left(s-t-(1 / N)^{n-2}\right.}{(n-2) !} f\left(s, x_{0, N}(s), \cdots, x_{n-1, N}(s)\right) d s \\
x_{0, N}(t) & =c-\int_{t+(1 / N)}^{\infty} \frac{\left(s-t-(1 / N)^{n-1}\right.}{(n-1) !} f\left(s, x_{0, N}(s), \cdots, x_{n-1, N}(s)\right) d s .
\end{aligned}
$$

This formula defines $x_{i, N}(t)$ for $i=0,1, \cdots, n-1$, successively on the intervals $[N-(K / N), N-(K-1) / N]$ for $k=1,2, \cdots, N(N-T)$ : hence $x_{i, N}(t), i=0,1, \cdots, n-1$, are defined on $[T, \infty)$. For $N-(1 / N) \leqq t<\infty$, we have by (6)

$$
\begin{aligned}
\left|x_{i, N}(t)-k_{i+1}\right| & \leqq \int_{t+(1 / N)}^{\infty} \frac{(s-t-(1 / N))^{n-1-i}}{(n-1-i) !} f\left(s, x_{0, N}(s), \cdots, x_{n-1, N}(s)\right) d s \\
& \leqq \int_{t+(1 / N)}^{\infty} \frac{(s-t-(1 / N))^{n-1-i}}{(n-1-i) !} f\left(s, c, k_{2}, \cdots, k_{n}\right) d s \\
& \leqq \frac{c}{M}(i=1,2, \cdots, n-1)
\end{aligned}
$$

and also

$$
0<c-\frac{c}{M} \leqq x_{0, N}(t) \leqq c
$$

By easy induction, we have

$$
0 \leqq\left|x_{i, N}(t)-k_{i+1}\right| \leqq \frac{c}{M} i=1,2, \cdots, n-1,
$$

$$
0<c-\frac{c}{M} \leqq x_{0, N}(t) \leqq c
$$

on the entire interval $[T, \infty)$. Consequently, for $t \geqq T$, since $f$ is generalized strongly continuous and $f\left(t, c, k_{2}, \cdots, k_{n}\right)$ is bounded, we have

$$
\begin{aligned}
\left|x_{n-1^{\prime}, N}(t)\right| & =f\left(t+\frac{1}{N}, x_{0, N}\left(t+\frac{1}{N}\right), \cdots, x_{n-1, N}\left(t+\frac{1}{N}\right)\right) \\
& \leqq \frac{3}{2} f\left(t+\frac{1}{N}, c, k_{2}, \cdots, k_{n}\right) \\
& \leqq \frac{3}{2} K(K \text { is constant }),
\end{aligned}
$$




$$
\left|x_{i, N}^{\prime}(t)\right|=\left|x_{i+1, N}(t)-k_{i+2}\right| \leqq \frac{c}{M}, \quad(i=0,1, \cdots, n-2) .
$$

Since the family $\left\{x_{i, N}(t)\right\}(i=0,1,2, \cdots, n-1)$, is uniformly bounded and equicontinuous on $[T, B]$ ( $B$ is arbitrary), we extract from $\left\{x_{i(N}(t)\right\}$ $(i=0,1, \cdots, n-1)$, a uniformly convergent subsequence $\left\{x_{i, k}(t)\right\}$,

$$
\lim _{k \rightarrow \infty} x_{i, k}(t)=\bar{x}_{i}, \quad \text { (on }[T, B], \text { for } i=0,1 \cdots, n-1 \text { ). }
$$

For any large number $B>T$, we may write (8) in the form

$$
\begin{aligned}
x_{i, k}(t)= & d+(-1)^{i+1}\left\{\int _ { t + ( 1 / k ) } ^ { B } \frac { ( s - t - ( 1 / k ) ) ^ { n - 1 - i } } { ( n - 1 - i ) ! } f \left(s, x_{0, k}(s),\right.\right. \\
& \left.\left.\cdots, x_{n-1, k}(s)\right) d s+\phi_{k}(B)\right\}
\end{aligned}
$$

where,

$$
\begin{aligned}
\phi_{k}(\mathrm{~B}) & =\int_{B}^{\infty} \frac{(s-t-(1 / k))^{n-1-i}}{(n-1-i) !} f\left(s, x_{0, k}(s), \cdots, x_{n-1, k}(s)\right) d s, \\
(d & \left.=c \text { for } i=0, d=k_{i+1} \text { for } i=1,2 \cdots, n-1\right) .
\end{aligned}
$$

For fixed $B$ we let $k$ tend to infinity in (11) and obtain

$$
\begin{gathered}
\liminf _{k \rightarrow \infty} \phi_{k}(B) \leqq(-1)^{i}\left(-\bar{x}_{i}+d+(-1)^{i+1} \int_{t}^{B} \frac{(s-t)^{n-1-i}}{(n-1-i) !} f\left(s, \bar{x}_{0}\right.\right. \\
\left.\left.\cdots, \bar{x}_{n-1}\right) d s\right) \leqq \lim _{k \rightarrow \infty} \sup \phi_{k}(B) .
\end{gathered}
$$

From (6) and (9) and $f$ is generalized strongly continuous, we obtain

$$
\begin{aligned}
0 & \leqq \phi_{k}(B)=\int_{B}^{\infty} \frac{(s-t-(1 / k))^{n-1-i}}{(n-1-i) !} f\left(s, x_{0 k}(s), \cdots, x_{n-1, k}(s)\right) d s \\
& \leqq \frac{3}{2} \int_{B}^{\infty} \frac{(s-t)^{n-1-i}}{(n-1-i) !} f\left(s, c, k_{2}, \cdots, k_{n}\right) d s<\infty .
\end{aligned}
$$

By (2), the integral in (12) tend to zero as $B \rightarrow \infty$. Thus, we conclude that $\bar{x}_{i}(t)(i=0,1, \cdots, n-1)$, is a solution of (5) and also $\bar{x}_{0}(t)$ is a bounded nonoscillatory solution of (1).

Theorem 2. Assume that $n$ is even and that

( $\beta$ ) $x_{1} f\left(t, x_{1}, x_{2}, \cdots, x_{n-1}, \gamma\right)>0\left(x_{1} \neq 0\right)$, where $\gamma$ is constant.

Let $f\left(t, x_{1}, x_{2}, \cdots, x_{n-1}, \gamma\right)$ be generalized strongly continuous from the left for $x_{1}>0$, and generalized strongly continuous from the right for $x_{1}<0$. Then, a necessary and sufficient conditior for equation

$$
x^{(n)}+f\left(t, x, x^{\prime}, \cdots, x^{(n-2)}, \gamma\right)=0(\gamma \text { is constant }),
$$


to have a bounded nonoscillatory solution is

$$
\left|\int^{\infty} t^{n-1} f\left(t, c, k_{2}, \cdots, k_{n-1}, \gamma\right) d t\right|<\infty
$$

$\left(c(\neq 0)\right.$ and $k_{i}(i=2, \cdots, n-1)$ are some constant $)$.

Proof. The necessity follows from the necessary part of the proof of Theorem 1.

Conversely, we show that if $\left(2^{\prime}\right)$ holds for some constant $c>0$ and $k_{i}(i=2, \cdots, n-1)$, then there exists a nonnegative continuous bounded solution to the following integral equation:

$$
\begin{aligned}
& x_{n-2}(t)=k_{n-1}-\int_{t}^{\infty}(s-t) f\left(s, x_{0}(s), \cdots, x_{n-2}(s), \gamma\right) d s \\
& x_{n-3}(t)=k_{n-2}+\int_{t}^{\infty} \frac{(s-t)^{2}}{2 !} f\left(s, x_{0}(s), \cdots, x_{n-2}(s), \gamma\right) d s \\
& \vdots \\
& x_{0}(t)=c-\int_{t}^{\infty} \frac{(s-t)^{n-1}}{(n-1) !} f\left(s, x_{0}(s), \cdots, x_{n-1}(s), \gamma\right) d s .
\end{aligned}
$$

Let a positive number $T$ be chosen such that

$$
\max _{i \in E} \int_{T}^{\infty} \frac{(s-t)^{n-1-i}}{(n-1-i) !} f\left(s, c, k_{2}, \cdots, k_{n-1}, \gamma\right) d s \leqq \frac{c}{M}
$$

$(M(>2)$ is some constant).

We define, for $N$ a positive integer $N \geqq T$ : for $t \geqq N$,

$$
\begin{gathered}
x_{n-2, N}(t)=k_{n-1} \\
\vdots \\
x_{1, N}(t)=k_{2} \\
x_{0, N}(t)=c
\end{gathered}
$$

and for $T \leqq t \leqq N$

$$
\begin{gathered}
x_{n-2, N}(t)=k_{n-1}-\int_{t+(1 / N)}^{\infty}\left(s-t-\frac{1}{N}\right) f\left(s, x_{0, N}(s), \cdots, x_{n-2, N}(s), \gamma\right) d s \\
\vdots \\
x_{1, N}(t)=k_{2}+\int_{t+(1 / N)}^{\infty} \frac{(s-t-(1 / N))^{n-2}}{(n-2) !} f\left(s, x_{0 N}(s), \cdots, x_{n-2, N}(s), \gamma\right) d s \\
x_{0, N}(t)=c-\int_{t+(1 / N)}^{\infty} \frac{(s-t-(1 / N))^{n-1}}{(n-1) !} f\left(s, x_{0, N}(s), \cdots, x_{n-2, N}(s) ; \gamma\right) d s .
\end{gathered}
$$

As same as the proof of Theorem $1, x_{i, N}(t)(i=0,1, \cdots, n-2)$, are defined on $[T, \infty)$ and that for $i=0,1, \cdots, n-3$, 


$$
\left|x_{i, N}^{\prime}(t)\right|=\left|x_{i+1, N}(t)-k_{i+2}\right| \leqq \frac{c}{M}
$$

and for $i=n-2$,

$$
\left|x_{i, N}^{\prime}(t)\right|=\int_{t}^{\infty} f\left(s, x_{0, N}(s), \cdots, x_{n-2, N}(s), \gamma\right) d s \leqq \frac{c}{M} \cdot
$$

Hence the family $\left\{x_{i, N}(t)\right\}(i=0,1, \cdots, n-2)$ is uniformly bounded and equicontinuous on $[T, B]$ ( $B$ is arbitrary). Using an argument similar to that given in the proof of Theorem 1, we hove a bounded nonoscillatory solution of $\left(1^{\prime}\right)$.

REMARK. For $n=2$, Theorem 2 coincides with Theorem 3 in [8].

Corollary 1. Suppose that $n$ is even and that

$$
x_{1} f\left(t, x_{1}, \cdots, x_{n}\right)>0 \quad\left(x_{1} \neq 0\right) \text {. }
$$

Let $f\left(t, x_{1}, \cdots, x_{n}\right)$ be generalized strongly continuous from the left for $x_{1}>0$ and generalized strongly continuous from the right for $x_{1}<0$ and that

$$
\left|\int_{t_{0}}^{\infty} t^{n-1} f\left(t, c, k_{2}, \cdots, k_{n}\right) d t\right|=+\infty\left(c(\neq 0) \text { and } k_{i}(i=2, \cdots, n)\right.
$$

are any constants). Then, every bounded solution of (1) is oscillatory.

Proof. The proof of Corollary 1 follows immediately from the necessary part of Theorem 1.

Corollary 2 [1, Theorem 1]. Consider

$$
x^{(2 n)}+p(t) g\left(x, x^{\prime}, x^{(2)}, \cdots, x^{(2 n-1)}\right)=0
$$

under the following assumption:

(i) $\quad p: \quad I \rightarrow R_{+}=(0,+\infty), \quad I=\left[t_{0},+\infty\right), \quad t_{0} \geqq 0, \quad p \in C\left[t_{0},+\infty\right)$, and

$$
\int_{t_{0}}^{+\infty} t^{2 n-1} p(t) d t=+\infty
$$

is satisfied;

(ii) $g: R^{2 n} \rightarrow R=(-\infty, \infty), \quad x_{1} g\left(x_{1}, x_{2}, \cdots, x_{2 n}\right)>0$ for $x_{1} \neq 0$, and continuous on $R^{2 n}$;

then, under the above conditions, every bounded solution of (15) is oscillatory. 
Proof. The function $p(t) g\left(x_{1}, x_{2}, \cdots, x_{2 n}\right)$ is generalized strongly continuous. Hence, Corollary 2 is included in Corollary 1.

CoRollary 3 [4, Theorem 1]. Under the assumption $\left(\alpha^{\prime}\right) \quad p(t)$ is bounded and eventually nonnegative:

$$
x_{1} g\left(x_{1}, x_{2}, \cdots, x_{2 n}\right)>0 \quad\left(x_{1} \neq 0\right), \quad \text { for } \quad\left(x_{1}, x_{2}, \cdots, x_{2 n}\right) \in R^{2 n},
$$

a necessary and sufficient condition that (15) have a bounded nonoscillatory solution is

$$
\int^{\infty} t^{2 n-1} p(t) d t<\infty
$$

Proof. The function $p(t) g\left(x_{1}, x_{2}, \cdots, x_{n}\right)$ is generalized strongly continuous, hence Corollary 3 is included in Theorem 1.

CoRollary 4 [4, Theorem 2]. Under the assumption $\left(\beta^{\prime}\right) \quad p(t)$ is eventually nonegative and $x_{1} g\left(x_{1}, x_{2}, \cdots, x_{2 n-1}, c\right)>0 x_{1} \neq 0$, for $\left(x_{1}, x_{2}, \cdots, x_{2 n-1}, c\right) \in R^{2 n}$ where $c$ is constant, a necessary and sufficient condition that the differential equation

$$
x^{(2 n)}+p(t) g\left(x, x^{\prime}, \cdots, x^{(2 n-2)}, c\right)=0, \quad n \geqq 1,
$$

$c$ is constant, have a bounded nonoscillatory solution is (16).

Proof. The proof follows immediately from Theorem 2.

THEOREM 3. Consider

$$
x^{(2 n)}+p(t) g(x)=0,
$$

under the following assumptions:

(i ) $\quad p: \quad I \rightarrow R_{+}=(0,+\infty), \quad I=\left[t_{0},+\infty\right), \quad t_{0} \geqq 0, \quad p \in C\left[t_{0},+\infty\right)$, (ii) $g: \quad R \rightarrow R=(-\infty,-\infty), g \in C^{\prime}(-\infty,+\infty), x g(x)>0$ for $x \neq 0$, and continuous on $R$;

$g^{\prime}(x) \geqq 0$ for $|x| \in[K,+\infty)$ ( $K$ is some positive constant), and

$$
\int_{\varepsilon}^{+\infty} \frac{1}{g(u)} d u<+\infty, \quad \int_{-\varepsilon}^{-\infty} \frac{1}{g(u)} d u<+\infty
$$

for every $\varepsilon>0$;

then a necessary and sufficient condition that every solution of (18) is oscillatory is

$$
\int_{t_{0}}^{+\infty} t^{2 n-1} p(t) d t=+\infty
$$


Proof. From Theorem 2, if $\int_{t_{0}}^{+\infty} t^{2 n-1} p(t) d t<+\infty$, then (18) is nonoscillatory. Hence we conclude that if every solution of (18) is oscillatory, then $\int_{t_{0}}^{+\infty} t^{2 n-1} p(t) d t=+\infty$.

Conversely $\int_{t_{0}}^{+\infty} t^{2 n-1} p(t) d t=+\infty$, then every solution of (18) is oscillatory in the case $n>1$ [1] and $n=1$ [6; 7].

THeOREM 4. Assume that $n$ is even and that $(\beta)$. Let $f\left(t, x_{1}, \cdots\right.$, $\left.x_{n-1}, \gamma\right)$ be generalized strongly continuous from the left for $x_{1}>0$, and generalized strongly continuous from the right for $x_{1}<0$. Then, a necessary and sufficient condition for every bounded solution of (1') to be oscillatory is

$$
\begin{aligned}
& \left|\int^{\infty} t^{n-1} f\left(t, c, k_{2}, \cdots, k_{n-1}, \gamma\right) d t\right|=+\infty \\
& \quad\left(c(\neq 0) \text { and } k_{i}(i=2, \cdots, n-1) \text { are any constant }\right) .
\end{aligned}
$$

Proof. Assume that (20) does not hold, then (2') holds for some $c \neq 0$ and $k_{i}(i=2, \cdots, n-1)$. Hence by Theorem 2, equation ( $\left.1^{\prime}\right)$ has a bounded nonoscillatory solution, so clearly condition (20) is necessary. Conversely, let $x(t)>0$ be a nonoscillatory solution of $\left(1^{\prime}\right)$. In view of the arguments of Theorem $1, x(t)$ must be nondecreasing and the limit is finite. Hence the argument in the proof of Theorem 1 is applicable, which shows that leads a contradiction.

THEOREm A [5]. If in addition to the hypothesis of Corollary 3 (or Corollary 4), for some $r>1$ and $n$ is even,

$$
\liminf _{\left|x_{1}\right| \rightarrow+\infty} \frac{\left|g\left(x_{1}, x_{2}, \cdots, x_{n}\right)\right|}{\left|x_{1}\right|^{r}}>0
$$

then a necessary and sufficient condition that all solution of (15) (or (17)) be oscillatory is

$$
\int^{\infty} t^{n-1} p(t) d t=+\infty
$$

Theorem B [2]. Consider

$$
x^{(n)}+p(t) g\left(x, x^{\prime}, \cdots, x^{(n-1)}\right)=0
$$

with $n$ even, and moreover,

(i) $p: \quad I \rightarrow R_{+}=(0,+\infty), \quad I=\left[t_{0},+\infty\right), \quad t_{0} \geqq 0$.

(ii) $g: R^{n} \rightarrow R=(-\infty,+\infty)$, and such that Condition $(G)$ :

$x_{1} g\left(x_{1}, x_{2}, \cdots, x_{n}\right)>0$ for every $\left(x_{1}, x_{2}, \cdots, x_{n}\right) \in R^{n}$ with $x_{1} \neq 0$, 
and for every $\left(x_{1}, x_{2}, \cdots, x_{n}\right) \in R^{n}$, and every $\lambda \geqq K$ (=fixed positive constant), $g\left(-x_{1},-x_{2}, \cdots,-x_{n}\right)=-g\left(x_{1}, x_{2}, \cdots, x_{n}\right)$, and $g\left(\lambda, \lambda x_{2}, \cdots, \lambda x_{n}\right)=\lambda^{\gamma} g\left(1, x_{2}, \cdots, x_{n}\right)$, where $\gamma=q / r, \quad q \quad r \quad$ odd positive integers relatively prime;

then under any one of the following conditions, all solutions of (23) are oscillatory:

$$
\begin{aligned}
& 0<\gamma<1, \int_{t_{0}}^{\infty} t^{\gamma(n-1)} p(t) d t=+\infty ; \\
& \gamma=1, \quad \int_{t_{0}}^{\infty} t^{n-1-\varepsilon} p(t) d t=+\infty, \\
& \text { for some } \varepsilon \text { with } 0<\varepsilon<1 ;
\end{aligned}
$$

$$
\gamma>1, \quad \int_{t_{0}}^{\infty} t^{n-1} p(t) d t=+\infty \text {. }
$$

Kartsatos [2, Remark 3] posed a problem that under what additional assumptions on the function $g$, the conditions of Theorem B are also necessary for the theorem to hold. In case $0<\gamma<1$, the condition (a) is also necessary for theorem B to hold. When $\gamma=1$ (this is the linear case), it is well known that condition (b) can not be necessary. Consider the Euler equation. Thus, we answer the problem for $\gamma>1$.

THEOREM 5. In addition to the assumptions of Theorem $A$, assume $p(t)$ being bounded. Then (c) is necessary for all solutions of (23) to be oscillatory.

Proof. As $p(t)$ being bounded, the proof follows immediately from Theorem 1 .

\section{Theorem 6. Consider the equation}

$$
x^{(n)}+p(t) g\left(x, x^{\prime}, \cdots, x^{(n-2)}, \delta\right)=0 \text { (for } n \text { even), }
$$

where $\delta$ is constant. Then (c) is necessary for all solutions of (24) to be oscillatory.

Proof. The proof follows immediately from Theorem 2.

Remarks. Theorem 5 and Theorem 6 are proved also from Theorem A, since from Condition $(G)$, we see

$$
\liminf _{\left|x_{1}\right| \rightarrow+\infty} \frac{\left|g\left(x_{1}, x_{2}, \cdots, x_{n-1}\right)\right|}{\left|x_{1}\right|^{r}}=\liminf _{\left|x_{1}\right| \rightarrow+\infty} \frac{\left|x_{1}\right|^{r} g\left(1,\left(x_{2} / x_{1}\right), \cdots,\left(x_{n-1} / x_{1}\right)\right)}{\left|x_{1}\right|^{r}}>0 .
$$

In case $0<\gamma<1$, Ličko and Švec [3] proved Theorem 6 with 
$g=x^{\gamma}(0<\gamma<1)$.

The author wishes to express his thanks to the referee for some very useful comments.

\section{REFERENCES}

1. A. G. Kartsatos, On oscillation of solutions of even order nonlinear differential equations, J. Differential Equations, 6 (1969), 232-237.

2. - Criteria for oscillation of solutions of differential equations of arbitrary order, Proc. Japan Acad., 44 (1968), 599-602.

3. I. Ličko and M. Švec, Le caractère oscillatoire des solutions de l'équation $y^{(n)}+f(x) y^{\alpha}=0, n>1$, Czechoslovak Math. J., 13 (1963), 481-491.

4. H. Onose, Oscillatory property of certain nonlinear ordinary differential equations, SIAM J. Appl. Math., 18 (1970), 715-719.

5. Oscillatory property of ordinary differential equations of arbitrary order, J. Differential Equations, 7 (1970), 454-458.

6. - Oscillation theorems for nonlinear second order differential equations Proc. Amer. Math. Soc., (in press).

7. J. W. Macki and J. S. W. Wong, Oscillation of solutions to second-order nonlinear differential equations, Pacific J. Math., 24 (1968), 111-117.

8. J. S. W. Wong, On second order nonlinear oscillation, Funkcial. Ekvac., 11 (1969), 207-234.

Received May 11, 1970.

UNIVERSity of Ibaraki, Hitachi, JAPAN. 



\title{
PACIFIC JOURNAL OF MATHEMATICS
}

\author{
EDITORS
}

\author{
H. Samelson \\ Stanford University \\ Stanford, California 94305 \\ C. R. HOBBY \\ University of Washington \\ Seattle, Washington 98105
}

J. DugundJI

Department of Mathematics

University of Southern California

Los Angeles, California 90007

RICHARD ARENS

University of California

Los Angeles, California 90024

\section{ASSOCIATE EDITORS}

E. F. BECKENBACH
B. H. NEUMANN

F. WoLF
K. YosHIDA

\section{SUPPORTING INSTITUTIONS}

\author{
UNIVERSITY OF BRITISH COLUMBIA \\ CALIFORNIA INSTITUTE OF TECHNOLOGY \\ UNIVERSITY OF CALIFORNIA \\ MONTANA STATE UNIVERSITY \\ UNIVERSITY OF NEVADA \\ NEW MEXICO STATE UNIVERSITY \\ OREGON STATE UNIVERSITY \\ UNIVERSITY OF OREGON \\ OSAKA UNIVERSITY \\ UNIVERSITY OF SOUTHERN CALIFORNIA
}

\author{
STANFORD UNIVERSITY \\ UNIVERSITY OF TOKYO \\ UNIVERSITY OF UTAH \\ WASHINGTON STATE UNIVERSITY \\ UNIVERSITY OF WASHINGTON \\ $\stackrel{*}{*} \stackrel{*}{*} \stackrel{*}{*}{ }^{*}{ }^{*}$ MERICAN MATHEMATICAL SOCIETY \\ CHEVRON RESEARCH CORPORATION \\ NAVAL WEAPONS CENTER
}

The Supporting Institutions listed above contribute to the cost of publication of this Journal, but they are not owners or publishers and have no responsibility for its content or policies.

Mathematical papers intended for publication in the Pacific Journal of Mathematics should be in typed form or offset-reproduced, (not dittoed), double spaced with large margins. Underline Greek letters in red, German in green, and script in blue. The first paragraph or two must be capable of being used separately as a synopsis of the entire paper. The editorial "we" must not be used in the synopsis, and items of the bibliography should not be cited there unless absolutely necessary, in which case they must be identified by author and Journal, rather than by item number. Manuscripts, in duplicate if possible, may be sent to any one of the four editors. Please classify according to the scheme of Math. Rev. Index to Vol. 39. All other communications to the editors should be addressed to the managing editor, Richard Arens, University of California, Los Angeles, California, 90024.

50 reprints are provided free for each article; additional copies may be obtained at cost in multiples of 50 .

The Pacific Journal of Mathematics is published monthly. Effective with Volume 16 the price per volume (3 numbers) is $\$ 8.00$; single issues, $\$ 3.00$. Special price for current issues to individual faculty members of supporting institutions and to individual members of the American Mathematical Society: $\$ 4.00$ per volume; single issues $\$ 1.50$. Back numbers are available.

Subscriptions, orders for back numbers, and changes of address should be sent to Pacific Journal of Mathematics, 103 Highland Boulevard, Berkeley, California, 94708.

PUBLISHED BY PACIFIC JOURNAL OF MATHEMATICS, A NON-PROFIT CORPORATION

Printed at Kokusai Bunken Insatsusha (International Academic Printing Co., Ltd.), 7-17, Fujimi 2-chome, Chiyoda-ku, Tokyo, Japan. 


\section{Pacific Journal of Mathematics}

J. T. Borrego, Haskell Cohen and Esmond Ernest Devun, Uniquely

representable semigroups on the two-cell .................. 565

Glen Eugene Bredon, Some examples for the fixed point property ........ 571

William Lee Bynum, Characterizations of uniform convexity .......... 577

Douglas Derry, The convex hulls of the vertices of a polygon of order $n \ldots 583$

Edwin Duda and Jack Warren Smith, Reflexive open mappings .......... 597

Y. K. Feng and M. V. Subba Rao, On the density of $(k, r)$ integers ........ 613

Irving Leonard Glicksberg and Ingemar Wik, Multipliers of quotients of

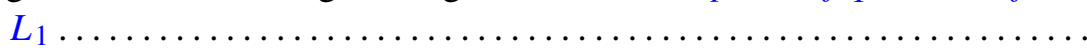

John William Green, Separating certain plane-like spaces by Peano

continua.........................................

Lawrence Albert Harris, A continuous form of Schwarz's lemma in normed

linear spaces .................................... 635

Richard Earl Hodel, Moore spaces and $w$-spaces ............... 641

Lawrence Stanislaus Husch, Jr., Homotopy groups of PL-embedding spaces.

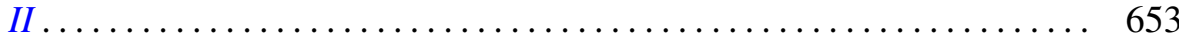

Yoshinori Isomichi, New concepts in the theory of topological

space-supercondensed set, subcondensed set, and condensed set.....

J. E. Kerlin, On algebra actions on a group algebra .................

669

Keizō Kikuchi, Canonical domains and their geometry in $C^{n} \ldots \ldots \ldots \ldots 681$

Ralph David McWilliams, On iterated $w^{*}$-sequential closure of cones. .

697

C. Robert Miers, Lie homomorphisms of operator algebras ..

717

Louise Elizabeth Moser, Elementary surgery along a torus knot ...

737

Hiroshi Onose, Oscillatory properties of solutions of even order differential

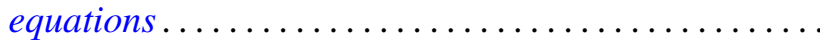

747

Wellington Ham Ow, Wiener's compactification and $\Phi$-bounded harmonic

functions in the classification of harmonic spaces...

Zalman Rubinstein, On the multivalence of a class of meromorphic

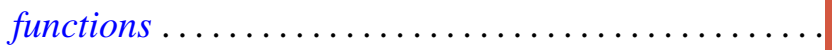

771

785

Hans H. Storrer, Rational extensions of modules

795

topological lattices ...........................

Robert Evert Stong, On the cobordism of pairs .................. 803
Albert Leon Whiteman, An infinite family of skew Hadamard matrices . . . 817

Lynn Roy Williams, Generalized Hausdorff-Young inequalities and mixed

norm spaces 